\title{
Endothelial mechanosensors: the gatekeepers of vascular homeostasis and adaptation under mechanical stress
}

\author{
DENG QiuPing ${ }^{\dagger}$, HUO YingQing ${ }^{\dagger} \&$ LUO JinCai ${ }^{*}$ \\ Laboratory of Vascular Biology, Institute of Molecular Medicine, Beijing Key Laboratory of Cardiometabolic Molecular Medicine, Peking \\ University, Beijing 100871, China
}

Received June 9, 2014; accepted July 5, 2014

\begin{abstract}
Endothelial cells (ECs) not only serve as a barrier between blood and extravascular space to modulate the exchange of fluid, macromolecules and cells, but also play a critical role in regulation of vascular homeostasis and adaptation under mechanical stimulus via intrinsic mechanotransduction. Recently, with the dissection of microdomains responsible for cellular responsiveness to mechanical stimulus, a lot of mechanosensing molecules (mechanosensors) and pathways have been identified in ECs. In addition, there is growing evidence that endothelial mechanosensors not only serve as key vascular gatekeepers, but also contribute to the pathogenesis of various vascular disorders. This review focuses on recent findings in endothelial mechanosensors in subcellular microdomains and their roles in regulation of physiological and pathological functions under mechanical stress.
\end{abstract}

endothelial cells, mechanotransduction, mechanosensors, vascular adaptation, vascular pathogenesis

Citation: Deng QP, Huo YQ, Luo JC. Endothelial mechanosensors: the gatekeepers of vascular homeostasis and adaptation under mechanical stress. Sci China Life Sci, 2014, 57: 755-762, doi: 10.1007/s11427-014-4705-3

As a monolayer (endothelium) on the inner surface of vascular wall, endothelial cells (ECs) are constantly exposed to mechanical stimuli including shear stress from blood flow and circumferential stretch from blood pressure. ECs are able to sense mechanical stress, convert it into intracellular biochemical signaling and respond by changing their own behaviors or cross-talk with surrounding cells in order to adapt to the mechanical stimulus. ECs-mediated adaptive signaling contributes to the establishment of structural and functional plasticity of vessels under various mechanical stimuli. It is already known that endothelial adaptive response is crucial to the maintenance of vascular homeostasis and the regulation of vascular adaptation under physiological conditions, while uncontrolled or excessive vascular adaptation has been regarded as one of the earliest events

$\dagger$ Contributed equally to this work

*Corresponding author (email: jincailuo@pku.edu.cn) leading to the generation of various pathological conditions $[1,2]$. Therefore, it has long been one of the main themes in vascular biology to study the cellular and molecular mechanisms underlying endothelial mecha- notransduction, a complex and dynamic process involving extracellular stimuli-sensing, intracellular signaling transduction and regulation of gene expression.

In the past years, significant progress has been made in this filed. A variety of endothelial mechanosensors, which are mostly associated with subcellular microdomains or organelles, have been identified; in addition, their downstream pathways, which may interact with each other at multiple levels, have been revealed [3-15]. The analysis of genetic and disease models demonstrated that endothelial mechanotransduction not only plays important roles in vascular adaptation or protection against mechanical stress, but also contributes to the pathogenesis of various vascular dis- 
orders [16-20]. In this brief review, we will discuss recent advances in endothelial mechanotransduction with a focus on endothelial mechanosensors and their physiol- ogical and pathological roles. It should be noted that the term of endothelial mechanosensors used in this review is a collection of subcellular microdomains-associated mechanosensing molecules of ECs reported in literatures; it remains to be determined at single molecule level whether they sense physical forces directly or indirectly.

\section{Subcellular microdomains and their associ- ated mechanosensors in ECs}

Because ECs are constantly subject to blood flow that has a frictional force and hydrostatic pressure, the search for the mechanosensors has attracted growing attention. Mechanotransduction is mostly initiated from the cell surface due to the deformation and/or fluidity alteration of plasma membrane by mechanical stimulus, transmitted along the cytoskeleton to sites of intercellular junctions and cellmatrix adhesions, and destined to the nucleus for transcriptional regulation [17], suggesting possible roles of these subcellular microdomains in mechanotransduction [21,22]. It has become increasingly clear that a variety of subcellular microdomains function as platforms of mechanosensors to sense and transduce mechanical stimulus. Below are major subcellular microdomains and their associated mechanosensors in ECs.

\subsection{Caveolae and lipid rafts}

Plasma membrane of cells has been organized by lipid rafts, which are enriched in cholesterol and sphingolipids, into various discrete microdomains called caveolae, omegashaped pits in the plasma membrane with a diameter of 60-80 nm [23-25]. Accumulated evidence suggests that caveolae act as platforms for conducting a variety of cellular functions including mechanotransduction [26-30]. Caveolin-1 (Cav-1) protein is one of major components in caveolae. A recent study showed that after exposure to shear stress for $24 \mathrm{~h}, \mathrm{Cav}-1 /$ caveolae were enhanced and concentrated across the apical aspects of ECs [26]. In contrast, after stretching vascular caveolae became flattened, which may not only serve as a buffering system to decrease membrane tension and prevent cell damage or lysis, but also trigger cell protective signaling [27,28]. Altered blood pressure and flow changed the gene expression and protein phosphorylation levels of resident caveolae proteins including caveolins and cavins [29]. Direct in vivo evidence for a role of caveolae in mechanotransduction was obtained from Cav-1 knockout mice [30]. The Cav-1 deficient mice displayed defects in both acute flow-dependent dilation and chronic flow-dependent remodeling. Because both effects were rescued by Cav-1 re-expression in the endothelium, Cav-1 appears to be a critical mechanosensing molecule in ECs [30,31]. Accumulated data suggest that caveolae and its associated molecules play multiple roles in vascular paradigms via mechanotransduction $[32,33]$.

\subsection{Membrane proteins: ion channels and receptors}

Several types of membrane proteins, such as some ion channels, VEGFR2 and $\mathrm{G}$ protein-coupled receptors (GPCRs), are known to sense and/or transduce mechanical stimuli in ECs. Although some of these membrane proteins are located at or associated with caveolae [32-35], their mechanotransducing functions are not necessarily related to subcellular microdomains. We thus use this section to discuss these proteins, focusing on ion channels and GPCRs.

More than two decades ago, it was proposed that ion channels are endothelial mechanotransducers [3]. Consistent with this, shear stress was shown to activate $\mathrm{K}^{+}$current in ECs [36], which was later found to mediate the secretion of vasodilators [37] and gene expression [38]. Following these findings, shear stress was also shown to be able to activate calcium transients [39]; stretch was found to activate non-selective cation channels in ECs [40]. It has already been known that multiple mechanosensing ion channels, including stretch-activated (TRPC1 and TRPV2), shear stress-activated (TRPV4 and TRPP1/2), and pressure- activated (TRPM4 and TRPC6) channels are expressed in ECs [41]. It is worth noting that mechanical stimuli may activate other signaling molecules that indirectly activate ion channels, as clearly shown in the case of TRPV4 activation by cell swelling [42].

An early study showed that mechanical stimulus activated specific GTP binding proteins (G proteins) in ECs within $1 \mathrm{~s}$ of flow onset, representing one of the earliest mechanochemical signal transduction events reported to date in shear-stimulated endothelium [5]. A recent study showed that $G$ alpha $(q / 11)$, the heterotrimeric $G$ protein subunits, form a protein complex with PECAM-1, another mechanosensing molecule in cellular junction involved in rapid mechanosensing response of ECs [43]. Interestingly, G alpha $(\mathrm{q} / 11)$ was absent from junctions in atheroprone areas as well as in all arterial sections of PECAM-1 knockout mice, suggesting that the G alpha (q/11)-PECAM- 1 complex is a critical mediator of vascular diseases [43]. The activation of $\mathrm{G}$ proteins may be directly [44] or indirectly triggered by GPCRs under flow stimulus [45]. Recently, the chemokine receptors CXCR1 and CXCR2, known as G protein-coupled receptors required for migratory response of ECs toward the shear stress- dependent CXCL8 (Interleukin-8), are potentially novel mechanosensors in ECs for hemodynamic forces [46]. The detailed role of these receptors in mechanotransduction awaits further investigation. 


\subsection{Primary cilia}

A primary cilium, which connects to the cytoskeletal microtubules of the cells doublets via the basal body of the cell, protrudes from the cell into the lumen of the vessel with the length of proximately $1-5 \mu \mathrm{m}$. Primary cilium is increasingly regarded as a mechanosensing organelle in several cellular systems including ECs [47]. Primary cilia in ECs exposed to unidirectional fluid flow bend in the direction of flow. In addition, ECs with cilia displayed a stronger response to shear stress in vitro than those without cilia [48]. It is known that mechanosensing molecules, such as polycystins and integrins are present in cilia of ECs. Consistently, ECs without primary cilia failed to convert mechanical stimulus into intracellular calcium and nitric oxide signaling in ECs [49]. Interestingly, fluid flow has been shown to cause loss of primary cilia from the endothelial surface [50], suggesting a feedback between mechanical stimulus and ciliary structure [51]. A recent study indicated that loss of primary cilia primed shear-induced endothelial-to-mesenchymal transition, indicating a functional link between primary cilia and flow-related endothelial performance [52].

\subsection{Glycocalyx}

Glycocalyx, a mesh-like structure of hydrated proteoglycans and glycosaminoglycans, covers the luminal side of ECs in both arteries and veins. Glycocalyx thickness increases with vessel diameter, ranging from 2 to $4.5 \mu \mathrm{m}$ in arteries [53,54]. In addition to be a barrier that determines the vascular permeability and restricts the molecules and leukocytes from reaching the endothelium, glycocalyx is also involved in endothelial mechanotransduction. Flow stimulus modulated the production and distribution of glycocalyx [55]. After exposure to shear stress for $24 \mathrm{~h}$, the glycocalyx components, e.g., heparan sulfate, chondroitin sulfate, glypican-1 and syndecan-1, were enhanced and associated with the changes in membrane rafts and the actin [26]. In contrast, the removal of glycocalyx by heparitinase significantly reduced flow-induced endothelial responses [8,56,57]. The redistribution of the glycocalyx also appears to act as a cell-adaptive mechanism by reducing the shear gradients that the cell surface experiences, which play a central role in mediating fluid shear stress-induced cell motility and proliferative response [26,55]. Further in vivo study found that the glycocalyx is present as soon as blood flow is initiated, which contributes to normal vascular development [58]. Evidence has been provided to show the glycocalyx is the first line of defence against atheror- ombotic disease and specifically its dysfunction is thought to be the first step during atherothrombosis [59].

\subsection{Cellular junction and adhesion molecules}

Endothelial cellular junctions include tight, gap and ad- herens junctions that are mediated by occludin/claudins, connexins and VE-cadherin, respectively [60]. These junction molecules have been proposed as putative mechanotransducers, which are able to sense blood flow [61]. A mechanosensory complex of proteins at cellular junctions, which include PECAM-1, VE-cadherin and VEGFR2, has been well studied in flow and stretch-mediated mechanotransduction in ECs [2,62-65]. Cellular adhesion to the surrounding extracellular environment is essential to numerous aspects of cellular physiology including mechanobiology. Focal adhesions constitute discrete contact sites where integrin receptors connect the extracellular filamentous meshwork to the intracellular cytoskeleton, mediating bidirectional mechanical transduction through endothelial cell [66]. The integrins in ECs are known to be mechanotransducers critically involved in force-sensing processes by exerting their action between the extracellular matrix and the contractile actomyosin cytoskeleton [67]. Notably, integrin ligation by matrix proteins at focal adhesions in ECs is possibly required to initiate the signaling pathway leading to shear stress-induced vasodilation and blood pressure regulation $[6,68,69]$. As a key focal adhesion component and intracellular signaling transducer, the role of focal adhesion kinase (FAK) in endothelial mechanotransduction has been mostly studied. Mechanical stretch rapidly increased tyrosine phosphorylation of FAK [70]. Up to now, the studies have showed that FAK is involved in endothelial responses to various patterns of mechanical stimuli including cyclic stretch and shear stress, regulating vascular cell proliferation, remodeling and vascular inflammation [71].

\subsection{Other subcellular microdomains}

In order to effectively and coordinately sense, transmit and respond to mechanical stimuli, other parts/compartments, such as cytoskeleton and nuclei, of cells also play important roles [72-74]. Cytoskeletal components determine and maintain cell shape and integrity. Mechanical stimuli, such as shear stress and stretch, cause to some extent the changes of cellular morphology, which exerts effects on interconnected network of cytoskeleton and triggers cellular response. A delicate study with a laser trap showed that the mechanical force even as small as $5.5 \mathrm{pN}$ applied to actin stress fibers was strong enough to trigger an influx of calcium ions, presumably owing to the activation of mechanosensitive ion channels in the plasma membrane [75]. Such a stimulus-response process may be very fast, sometimes at the speed of the order of hundreds of milliseconds [76]. Shear stress activates eNOS and endothelin-1 gene expression through a pathway involving the intermediate filament vimentin, the microtubule network and actin [77,78]. Interestingly, blood flow-induced vascular remodeling is facilitated by the genetic absence of the intermediate filaments, vimentin and desmin suggesting that these elements oppose the process $[79,80]$. Recent studies suggested that the nu- 
cleus is an important contributor to the overall mechanics of the cell [81]. The nucleus can serve as an intracellular "mechanostat", a structure that is able to sense and respond to changes in the mechanical properties of the cellular environment by changing its own stiffness [81,82]. A very recent study proposed that endothelial nucleus is a sensor of blood flow direction and strength via the hydrodynamic drag applied to their nuclei [15]. The detailed mechanism in nucleus-mediated mechanotransduction and its significance in vascular biology and in mechanical stress-related diseases need to be further explored.

\subsection{Features of mechanosensing and transducing sys- tem}

The localization of the mechanosensors in microdomains mentioned above is not absolute; in addition, their behaviors are dynamic. For example, caveolae harbor VEGFR2 [33] and PECAM-1 [34], which are known to be mechanosensors in cellular junctions [2,62,63]. Consistently, VEGFR2 activation was impaired in endothelial cells from Cav-1 KO mice [33]. Furthermore, the mechanosensing molecules frequently interact with each other. Recent studies showed that $\mathrm{G}$ alpha $(\mathrm{q} / 11)$, the heterotrimeric $\mathrm{G}$ protein subunits, form a protein complex with PECAM-1 to rapidly respond to mechanical stimuli $[43,83]$. Such dynamic and interactive feature allows the mechanosensors to finely and synergistically sense and respond to environmental stimuli.

Although mechanosensors transmit different signaling pathways, their downstream pathways are often integrated to activate some key enzymes or to induce the expression of a set of genes to perform certain functions. For example, the shear stress or acute stretch induced activation of eNOS, which is crucial in maintaining vascular homeostasis by dilating vessel and inhibiting inflammatory responses, can be finely-tuned by several upstream kinases [84,85]. The production of reactive oxygen species (ROS), a key molecule initiating many pro-atherogenic events, is tightly controlled by a variety of stimulatory and inhibitory pathways under various flow patterns and hypertensive stretch [86-88]. Similarly, the activity of $\mathrm{NF}-\kappa \mathrm{B}$, a critical pro-inflammatory nucleus factor, is modulated by several signaling pathways [89]. So far, however, little is known about the signaling adaptors that mediate signal transduction between mechanosensors and downstream pathways. The scaffolding molecules, i.e., Shc and Grb2-associated binding protein 1 may be the candidates as they are mechanosensitive and able to coordinate multiple signaling pathways from various receptors [6,90-94].

\section{Physiological and pathological roles of mechanosensors}

In the in vivo setting, endothelial mechanosensing system operates in the context of cell-cell contact and under various patterns of flow in blood vessels. Therefore, the mechanosensors in different ECs in different parts or organs appear to be heterogenous. It is known that in response to mechanical stress, ECs interact with vascular smooth muscle cells (VSMCs) [95,96]. Since VSMCs, which are also heterogenous throughout the vascular system, are able to control vessel diameter by contraction or relaxation via putative mechanosensors, i.e., DEG/ENaC proteins [97], the physical contact between ECs and VSMCs generates the heterogeneity of endothelial mechanosensors. Studies suggested that the expression of some mechanosensors is dependent on the location of the vessel and the local flow pattern. For example, the layer of glycocalyx in the internal carotid sinus region is thinner than that in the common carotid artery [16], whereas primary cilium is present in areas of low and disturbed flows in the adult aortic [98]. Accumulated results indicate that several types of hemodynamic forces are important in maintaining normal functions of the EC under physiological condition, while other types may lead to endothelial dysfunction under physiological status, contributing to the development of vascular diseases.

\subsection{Requirement of endothelial mechanosensors for vascular adaptation and remodeling}

Mechanical stress-induced immediate responses include biochemical changes, such as the activation of mechanosensors and secondary signaling pathways, increase in calcium concentration and nitric oxide release; cellular responses, such as membrane deformation, cytoskeletal remodeling and cell secretion; vessel changes, such as flow-mediated dilatation and pressure-mediated vascular tone. These responses serve to maintain vascular homeostasis through locally changing hemodynamics and prevent vascular cells from damage by mechanical injury $[65,85,99]$. Mechanical stress-induced sustained responses are relatively slow, adaptive and eventually lead to structural-wall remodeling, involving gene expression, cell differentiation and growth. Previous studies found that the vessel diameter is determined by an endothelium-dependent interplay between shear stress and the local pressure profile [100-102], suggesting the importance of endothelial mechanotransduction in sensing and transducing vascular mechanical stress in vascular remodeling. Consistently, lack of caveolae-mediated mechanotransduction impaired acute flow-dependent dilation and chronic flow-dependent remodeling [30].

2.2 The interaction between mechanosensors and mechanical stresses is an important determinant of vascular diseases

The geometric distribution of mechanical stress is closely associated with site-specific susceptibility to pathological changes $[1,2,18,103]$, such as atherosclerosis and inflamma- 
tion in arteries, suggesting the effects of mechanical stress on the phenotypic changes of ECs and vascular wall. Clinical studies suggested that the sites of atherosclerosis are not random, but preferentially located at arterial branches and curvatures where the local flow is disturbed. The effects of disturbed flow on vascular homeostasis, the signaling pathways and the involvements in pathological conditions have been well studied. For the details, please refer to recent excellent reviews $[1,2,89,104]$. On the other hand, recent studies showed that the increased density and expression of mechanosensors could initiate the mal-adaptation of vessels $[105,106]$. The pressure-activated cation channel upregulation in intact endothelium of aorta was suggested to contribute to severe genetic hypertension in a rat model [106]. Interestingly, PECAM-1-knockout mice did not activate $\mathrm{NF}-\kappa \mathrm{B}$ and downstream inflammatory genes in regions of disturbed flow, suggesting that this mechanosensing pathway is required for the earliest-known events in atherogenesis [63]. Therefore, the interaction between endothelial mechanosensors and mechanical stresses determines the site-specific susceptibility of vascular pathogenesis. So far, except for the atherosclerosis, which is well known to be associated with endothelial mechanotransduction [1,2], abnormal cilia function (ciliopathy) in ECs has been linked to renal diseases [107,108], while endothelial glycocalyx dysfunction has been regarded as a key factor in the develop- ment of microvascular hyperpermeability-related diseases $[109,110]$. It can be expected that in the near future, more and more mechanosensor-related diseases will be revealed.

The main feature of endothelial dysfunction is unable to sense the changes in hemodynamic forces and blood-borne signals, and to respond suitably. Besides, conventional risk factors were shown to damage mechanosensors [111]. In this regard, the suitable density and normal function of mechanosensors of ECs are the gatekeepers of cardiovascular functions. However, many vascular pathological changes are mediated through endothelial mechanosensing and transducing system [1]. Such opposite roles imply mechanosensors are double-edged swords, whose functions depend on the complex interactions among geometric mechanical stimuli, the expression and functional status of endothelial mechanosensors, and conventional risk factors.

\section{Perspectives}

In the last decades, with assembling of pieces of our understanding about mechanosensing and mechanotransducing process, a preliminary network of mechanosensing mechanisms and biological functions of mechanotransduction in ECs has gradually emerged (Figure 1). However, there are two major challenges in the field.

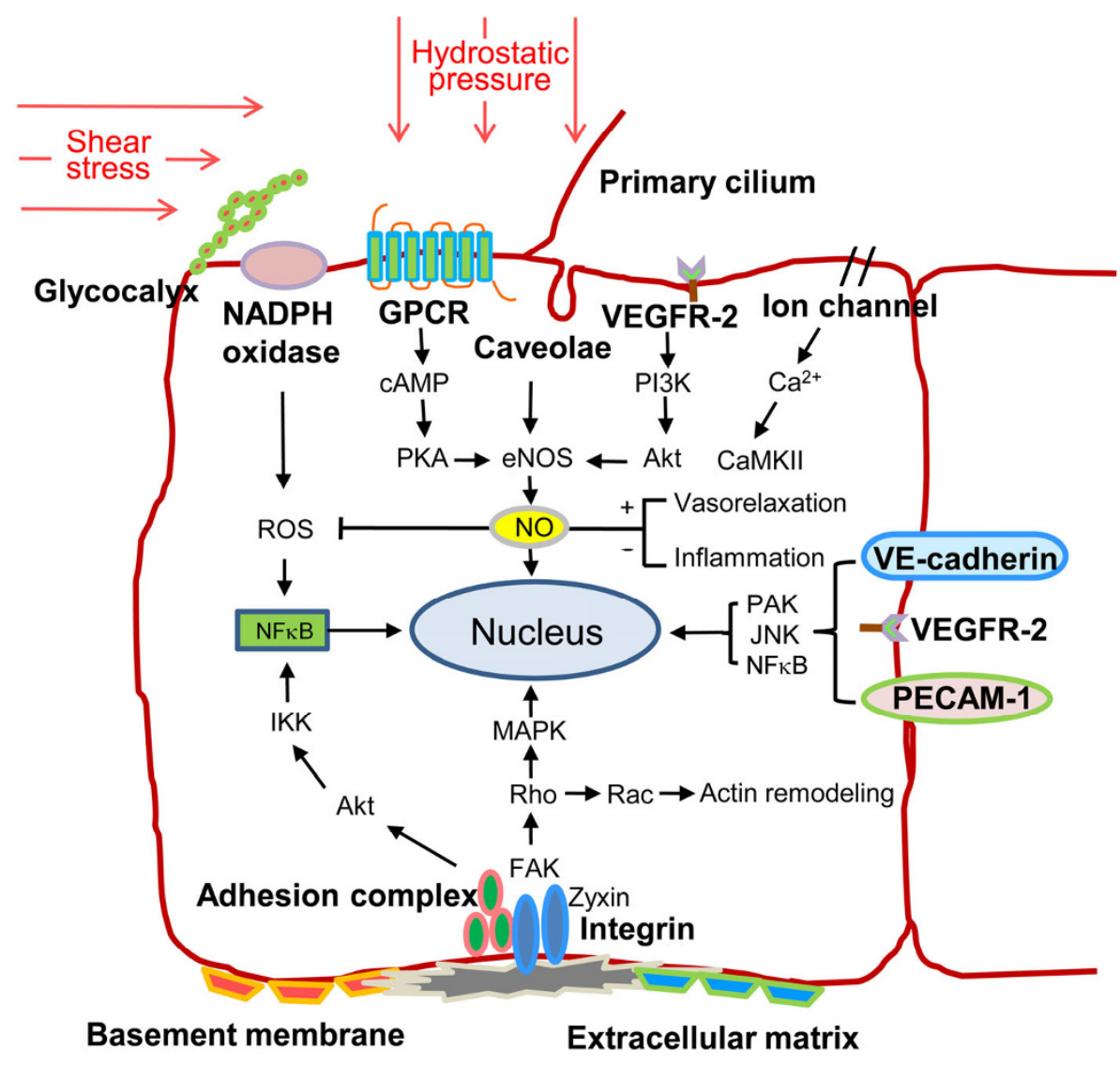

Figure 1 (color online) Endothelial mechanotransduction. Major mechanosensors and signaling pathways involved in EC mechanotransduction. 
The first challenge lies in the basic research aspect. A single endothelial mechanosensor unlikely exists; rather, mechanosensing and transducing process occurs at multiple subcellular microdomains. How do those multiple mechanosensors work together to effectively sense the mechanical stimulus and transmit into biochemical signaling pathways? How do ECs integrate multiple signaling pathways to exert functionally unified responses to mechanical stresses? How do ECs transmit mechanical signaling into surrounding cells, especially smooth muscle cells, to coordinate various responses to maintain vascular homeostasis and adapt to mechanical stress? To answer these questions, we need to use approaches from biophysics, molecular cell biology, physiology, developmental biology, bioengineering and bioinformatics to carry out comprehensive studies.

Another challenge comes from translational medicine research. With better understanding of endothelial mechanotransduction, we are prompted to develop new diagnostic, therapeutic and pharmacological approaches for treatment of cardiovascular diseases. Since current cardiovascular drugs are mostly aimed at lowering the risk factors (e.g., diabetes, hyperlipidemia, and hypertension), targeting at endothelial mechanosensors and/or intracellular regulators together could be more beneficial. Because those mechanosensors and signaling regulators are required for other fundamental cellular processes, caution should be rendered when translating the bench data into clinical applications.

This work was supported by the National Natural Science Foundation of China (91339111, 31221002) and National Basic Research Program of China (2012CB945100) to Luo JinCai.

1 Chiu JJ, Chien S. Effects of disturbed flow on vascular endothelium: pathophysiological basis and clinical perspectives. Physiol Rev, 2011, 91: $327-387$

2 Conway DE, Schwartz MA. Flow-dependent cellular mechanotransduction in atherosclerosis. J Cell Sci, 2013, 126: 5101-5109

3 Lansman JB, Hallam TJ, Rink TJ. Single stretch-activated ion channels in vascular endothelial cells as mechanotransducers? Nature, 1987, 325: 811-813

4 Wang N, Butler JP, Ingber DE. Mechanotransduction across the cell surface and through the cytoskeleton. Science, 1993, 260: 1124-1127

5 Gudi SR, Clark CB, Frangos JA. Fluid flow rapidly activates G proteins in human endothelial cells. Involvement of $\mathrm{G}$ proteins in mechanochemical signal transduction. Circ Res, 1996, 79: 834-839

6 Chen KD, Li YS, Kim M, Li S, Yuan S, Chien S, Shyy JY. Mechanotransduction in response to shear stress. Roles of receptor tyrosine kinases, integrins, and Shc. J Biol Chem, 1999, 274: 18393-18400

7 Ali MH, Schumacker PT. Endothelial responses to mechanical stress: where is the mechanosensor? Crit Care Med, 2002, 30: 198-206

8 Florian JA, Kosky JR, Ainslie K, Pang Z, Dull RO, Tarbell JM. Heparan sulfate proteoglycan is a mechanosensor on endothelial cells. Circ Res, 2003, 93: 136-142

9 Frank PG, Lisanti MP. Role of caveolin-1 in the regulation of the vascular shear stress response. J Clin Invest, 2006, 116: 1222-1225

10 Poelmann RE, Van der Heiden K, Gittenberger-de Groot A, Hierck BP. Deciphering the endothelial shear stress sensor. Circulation, 2008, 117: $1124-1126$

11 Tarbell JM, Ebong EE. The endothelial glycocalyx: a mechano-sensor and -transducer. Sci Signal, 2008, 1: 8
12 Barauna VG, Campos LC, Miyakawa AA, Krieger JE. ACE as a mechanosensor to shear stress influences the control of its own regulation via phosphorylation of cytoplasmic Ser(1270). PLoS ONE, 2011, 6: e22803

13 Zeng Y, Shen Y, Huang XL, Liu XJ, Liu XH. Roles of mechanical force and CXCR1/CXCR2 in shear-stress-induced endothelial cell migration. Eur Biophys J, 2012, 41: 13-25

14 Collins C, Guilluy C, Welch C, O’Brien ET, Hahn K, Superfine R, Burridge K, Tzima E. Localized tensional forces on PECAM-1 elicit a global mechanotransduction response via the integrin-RhoA pathway. Curr Biol, 2012, 22: 2087-2094

15 Tkachenko E, Gutierrez E, Saikin SK, Fogelstrand P, Kim C, Groisman A, Ginsberg MH. The nucleus of endothelial cell as a sensor of blood flow direction. Biol Open, 2013, 2: 1007-1012

16 Reitsma S, Slaaf DW, Vink H, van Zandvoort MA, oude Eqbrink MG. The endothelial glycocalyx: composition, functions, and visualization. Pflugers Arch, 2007, 454: 345-359

17 Davies PF. Hemodynamic shear stress and the endothelium in cardiovascular pathophysiology. Nat Clin Pract Cardiovasc Med, 2009, 6: 16-26

18 Zaragoza C, Márquez S, Saura M. Endothelial mechanosensors of shear stress as regulators of atherogenesis. Curr Opin Lipidol, 2012, 23: 446-452

19 Conway D, Schwartz MA. Lessons from the endothelial junctional mechanosensory complex. Biol Rep, 2012, 4: 1

20 Mammoto A, Mammoto T, Ingber DE. Mechanosensitive mechanisms in transcriptional regulation. J Cell Sci, 2012, 125: 3061-3073

21 Ingber DE. Cellular mechanotransduction: putting all the pieces together again. FASEB J, 2006, 20: 811-827

22 Ando J, Yamamoto K. Flow detection and calcium signalling in vascular endothelial cells. Cardiovasc Res, 2013, 99: 260-268

23 Simons K, Ikonen E. Functional rafts in cell membranes. Nature, 1997, 387: 569-572

24 Smart EJ, Graf GA, McNiven MA, Sessa WC, Engelman JA, Scherer PE, Okamoto T, Lisanti MP. Caveolins, liquid-ordered domains, and signal transduction. Mol Cell Biol, 1999, 19: 7289-7304

25 Galbiati F, Razani B, Lisanti MP. Emerging themes in lipid rafts and caveolae. Cell, 2001, 106: 403-411

26 Zeng Y, Tarbell JM. The adaptive remodeling of endothelial glycocalyx in response to fluid shear stress. PLoS ONE, 2014, 9: e86249

27 Sinha B, Köster D, Ruez R, Gonnord P, Bastiani M, Abankwa D, Stan RV, Butler-Browne G, Vedie B, Johannes L, Morone N, Parton RG, Raposo G, Sens P, Lamaze C, Nassoy P. Cells respond to mechanical stress by rapid disassembly of caveolae. Cell, 2011, 144: $402-413$

28 Gervásio OL, Phillips WD, Cole L, Allen DG. Caveolae respond to cell stretch and contribute to stretch-induced signaling. J Cell Sci, 2011, 124: 3581-3590

29 Radel C, Rizzo V. Integrin mechanotransduction stimulates caveolin-1 phosphorylation and recruitment of Csk to mediate actin reorganization. Am J Physiol Heart Circ Physiol, 2005, 288: 936-945

30 Yu J, Bergaya S, Murata T, Alp IF, Bauer MP, Lin MI, Drab M, Kurzchalia TV, Stan RV, Sessa WC. Direct evidence for the role of caveolin-1 and caveolae in mechanotransduction and remodeling of blood vessels. J Clin Invest, 2006, 116: 1284-1291

31 Murata T, Lin MI, Huang Y, Yu J, Bauer MP, Giordano FJ, Sessa WC. Reexpression of caveolin-1 in endothelium rescues the vascular, cardiac, and pulmonary defects in global caveolin-1 knockout mice. $\mathrm{J}$ Exp Med, 2007, 204: 2373-2382

32 Oh P, Schnitzer JE. Segregation of heterotrimeric G proteins in cell surface microdomains. Gq binds caveolin to concentrate in caveolae, whereas Gi and Gs target lipid rafts by default. Mol Biol Cell, 2001, 12: 685-698

33 Sonveaux P, Martinive P, DeWever J, Batova Z, Daneau G, Pelat M, Ghisdal P, Grégoire V, Dessy C, Balligand JL, Feron O. Caveolin-1 expression is critical for vascular endothelial growth factor-induced ischemic hindlimb collateralization and nitric oxide-mediated angiogenesis. Circ Res, 2004, 95: 154-161

34 Noel J, Wang H, Hong N, Tao JQ, Yu K, Sorokina EM, Debolt K, 
Heayn M, Rizzo V, Delisser H, Fisher AB, Chatterjee S. PECAM-1 and caveolae form the mechanosensing complex necessary for NOX2 activation and angiogenic signaling with stopped flow in pulmonary endothelium. Am J Physiol Lung Cell Mol Physiol, 2013, 305: L805-L818

35 Frank PG, Woodman SE, Park DS, Lisanti MP. Caveolin, caveolae, and endothelial cell function. Arterioscler Thromb Vasc Biol, 2003, 23: $1161-1168$

36 Olesen SP, Clapham DE, Davies PF. Haemodynamic shear stress activates a $\mathrm{K}^{+}$current in vascular endothelial cells. Nature, 1988, 331: $168-170$

37 Cooke JP, Rossitch E Jr, Andon NA, Loscalzo J, Dzau VJ. Flow activates an endothelial potassium channel to release an endogenous nitrovasodilator. J Clin Invest, 1991, 88: 1663-1671

38 Ohno M, Cooke JP, Dzau VJ, Gibbons GH. Fluid shear stress induces endothelial transforming growth factor beta-1 transcription and production. Modulation by potassium channel blockade. J Clin Invest, 1995, 95: 1363-1369

39 Schwarz G, Callewaert G, Droogmans G, Nilius B. Shear stress-induced calcium transients in endothelial cells from human umbilical cord veins. J Physiol, 1992, 458: 527-538

40 Popp R, Hoyer J, Meyer J, Galla HJ, Gögelein H. Stretch-activated non-selective cation channels in the antiluminal membrane of porcine cerebral capillaries. J Physiol, 1992, 454: 435-449

41 Yao X, Garland CJ. Recent developments in vascular endothelial cell transient receptor potential channels. Circ Res, 2005, 97: 853-863

42 Vriens J, Watanabe H, Janssens A, Droogmans G, Voets T, Nilius B. Cell swelling, heat, and chemical agonists use distinct pathways for the activation of the cation channel TRPV4. Proc Natl Acad Sci USA, 2004, 101: 396-401

43 Otte LA, Bell KS, Loufrani L, Yeh JC, Melchior B, Dao DN, Stevens HY, White CR, Frangos JA. Rapid changes in shear stress induce dissociation of a $\mathrm{G}$ alpha(q/11)-platelet endothelial cell adhesion molecule-1 complex. J Physiol, 2009, 587: 2365-2373

44 Gudi S, Nolan JP, Frangos JA. Modulation of GTPase activity of G proteins by fluid shear stress, and phospholipid composition. Proc Natl Acad Sci USA, 1998, 95: 2515-2519

45 Chachisvilis M, Zhang YL, Frangos JA. G protein-coupled receptors sense fluid shear stress in endothelial cells. Proc Natl Acad Sci USA, 2006, 103: 15463-15468

46 Zeng Y, Sun HR, Yu C, Lai Y, Liu XJ, Wu J, Chen HQ, Liu XH. CXCR1 and CXCR2 are novel mechano-sensors mediating laminar shear stress-induced endothelial cell migration. Cytokine, 2011, 53: 42-51

47 Nauli SM, Jin X, AbouAlaiwi WA, El-Jouni W, Su X, Zhou J. Non-motile primary cilia as fluid shear stress mechanosensors. Methods Enzymol, 2013, 525: 1-20

48 Hierck BP, Van der Heiden K, Alkemade FE, Van de Pas S, Van Thienen JV, Groenendijk BC, Bax WH, Van der Laarse A, Deruiter MC, Horrevoets AJ, Poelmann RE. Primary cilia sensitize endothelial cells for fluid shear stress. Dev Dyn, 2008, 237: 725-735

49 Nauli SM, Kawanabe Y, Kaminski JJ, Pearce WJ, Ingber DE, Zhou J. Endothelial cilia are fluid shear sensors that regulate calcium signaling and nitric oxide production through polycystin-1. Circulation, 2008, 117: 1161-1171

50 Iomini C, Tejada K, Mo W, Vaananen H, Piperno G. Primary cilia of human endothelial cells disassemble under laminar shear stress. J Cell Biol, 2004, 164: 811-817

51 Anderson CT, Castillo AB, Brugmann SA, Helms JA, Jacobs CR, Stearns T. Primary cilia: cellular sensors for the skeleton. Anat Rec, 2008, 291: 1074-1078

52 Egorova AD, Khedoe PP, Goumans MJ, Yoder BK, Nauli SM, ten Dijke P, Poelmann RE, Hierck BP. Lack of primary cilia primes shear-induced endothelial-to-mesenchymal transition. Circ Res, 2011, 108: 1093-1101

53 Van Haaren PM, VanBavel E, Vink H, Spaan JA. Localization of the permeability barrier to solutes in isolated arteries by confocal microscopy. Am J Physiol Heart Circ Physiol, 2003, 285: $\mathrm{H} 2848-\mathrm{H} 2856$
54 Megens RT, Reitsma S, Schiffers PH, Hilgers RH, De Mey JG, Slaaf DW, oude Egbrink MG, van Zandvoort MA. Two-photon microscopy of vital murine elastic and muscular arteries. J Vasc Res, 2007, 44: 87-98

55 Yao Y, Rabodzey A, Dewey CF Jr. Glycocalyx modulates the motility and proliferative response of vascular endothelium to fluid shear stress. Am J Physiol Heart Circ Physiol, 2007, 293: H1023-H1030

56 Mochizuki S, Vink H, Hiramatsu O, Kajita T, Shigeto F, Spaan JA, Kajiya F. Role of hyaluronic acid glycosaminoglycans in shear-induced endothelium-derived nitric oxide release. Am J Physiol Heart Circ Physiol, 2003, 285: H722-H726

57 Thi MM, Tarbell JM, Weinbaum S, Spray DC. The role of the glycocalyx in reorganization of the actin cytoskeleton under fluid shear stress: a “bumper-car' model. Proc Natl Acad Sci USA, 2004, 101: 16483-16488

58 Henderson-Toth CE, Jahnsen ED, Jamarani R, Al-Roubaie S, Jones EA. The glycocalyx is present as soon as blood flow is initiated and is required for normal vascular development. Dev Biol, 2012, 369: 330-339

59 Noble MI, Drake-Holland AJ, Vink H. Hypothesis: arterial glycocalyx dysfunction is the first step in the atherothrombotic process. QJM, 2008, 101: 513-518

60 Dejana E. Endothelial cell-cell junctions: happy together. Nat Rev Mol Cell Biol, 2004, 5: 261-270

61 Hahn C, Schwartz MA. Mechanotransduction in vascular physiology and atherogenesis. Nat Rev Mol Cell Biol, 2009, 10: 53-62

62 Shay-Salit A, Shushy M, Wolfovitz E, Yahav H, Breviario F, Dejana E, Resnick N. VEGF receptor 2 and the adherens junction as a mechanical transducer in vascular endothelial cells. Proc Natl Acad Sci USA, 2002, 99: 9462-9467

63 Tzima E, Irani-Tehrani M, Kiosses WB, Dejana E, Schultz DA, Engelhardt B, Cao G, DeLisser H, Schwartz MA. A mechanosensory complex that mediates the endothelial cell response to fluid shear stress. Nature, 2005, 437: 426-431

64 Liu J, Agarwal S. Mechanical signals activate vascular endothelial growth factor receptor-2 to upregulate endothelial cell proliferation during inflammation. J Immunol, 2010, 18: 1215-1221

65 Xiong Y, Hu Z, Han X, Jiang B, Zhang R, Zhang X, Lu Y, Geng C, Li W, He Y, Huo Y, Shibuya M, Luo J. Hypertensive stretch regulates endothelial exocytosis of Weibel-Palade bodies through VEGF receptor 2 signaling pathways. Cell Res, 2013, 23: 820-834

66 Geiger B, Spatz JP, Bershadsky AD. Environmental sensing through focal adhesions. Nat Rev Mol Cell Biol, 2009, 10: 21-33

67 Liu Z, Tan JL, Cohen DM, Yang MT, Sniadecki NJ, Ruiz SA, Nelson $\mathrm{CM}$, Chen CS. Mechanical tugging force regulates the size of cell-cell junctions. Proc Natl Acad Sci USA, 2010, 107: 9944-9949

68 Frame MD, Rivers RJ, Altland O, Cameron S. Mechanisms initiating integrin-stimulated flow recruitment in arteriolar networks. J Appl Physiol, 2007, 102: 2279-2287

69 Butler P, Wang Y. Editorial note: molecular imaging and mechanobiology. Cell Mol Bioeng, 2011, 4: 123-124

70 Naruse K, Yamada T, Sai XR, Hamaguchi M, Sokabe M. Pp125FAK is required for stretch dependent morphological response of endothelial cells. Oncogene, 1998, 17: 455-463

71 Zebda N, Dubrovskyi O, Birukov KG. Focal adhesion kinase regulation of mechanotransduction and its impact on endothelial cell functions. Microvasc Res, 2012, 83: 71-81

72 Helmke BP, Goldman RD, Davies PF. Rapid displacement of vimentin intermediate filaments in living endothelial cells exposed to flow. Circ Res, 2000, 86: 745-752

73 Osborn EA, Rabodzey A, Dewey CF Jr., Hartwig JH. Endothelial actin cytoskeleton remodeling during mechanostimulation with fluid shear stress. Am J Physiol Cell Physiol, 2006, 290: C444-C452

74 Deguchi S, Maeda K, Ohashi T, Sato M. Flow-induced hardening of endothelial nucleus as an intracellular stress-bearing organelle. J Biomech, 2005, 38: 1751-1759

75 Hayakawa K, Tatsumi H, Sokabe M. Actin stress fibers transmit and focus force to activate mechanosensitive channels. J Cell Sci, 2008, 121: 496-503 
76 Poh YC, Na S, Chowdhury F, Ouyang M, Wang Y, Wang N. Rapid activation of Rac GTPase in living cells by force is independent of Src. PLoS ONE, 2009, e7886

77 Morita T, Kurihara H, Maemura K, Yoshizumi M, Yazaki Y. Disruption of cytoskeletal structures mediates shear stress-induced endothelin-1 gene expression in cultured porcine aortic endothelial cells. J Clin Invest, 1993, 92: 1706-1712

78 Loufrani L, Henrion D. Role of the cytoskeleton in flow (shear stress)-induced dilation and remodeling in resistance arteries. Med Biol Eng Comput, 2008, 46: 451-460

79 Schiffers PM, Henrion D, Boulanger CM, Colucci-Guyon E, Langa-Vuves F, van Essen H, Fazzi GE, Lévy BI, De Mey JG. Altered flow-induced arterial remodeling in vimentin-deficient mice. Arterioscler Thromb Vasc Biol, 2000, 20: 611-616

80 Loufrani L, Li Z, Lévy BI, Paulin D, Henrion D. Excessive microvascular adaptation to changes in blood flow in mice lacking gene encoding for desmin. Arterioscler Thromb Vasc Biol, 2002, 22: $1579-1584$

81 Martins RP, Finan JD, Guilak F, Lee DA. Mechanical regulation of nuclear structure and function. Annu Rev Biomed Eng, 2012, 14: $431-455$

82 Swift J, Ivanovska IL, Buxboim A, Harada T, Dingal PC, Pinter J, Pajerowski JD, Spinler KR, Shin JW, Tewari M, Rehfeldt F, Speicher DW, Discher DE. Nuclear lamin-A scales with tissue stiffness and enhances matrix-directed differentiation. Science, 2013, 341: 1240104

83 dela Paz NG, Melchior B, Shayo FY, Frangos JA. Heparan sulfates mediate the interaction between platelet endothelial cell adhesion molecule-1 (PECAM-1) and the Gaq/11 subunits of heterotrimeric G proteins. J Biol Chem, 2014, 289: 7413-7424

84 Chien S. Mechanotransduction and endothelial cell homeostasis: the wisdom of the cell. Am J Physiol Heart Circ Physiol, 2007, 292: H1209-H1224

85 Hu Z, Xiong Y, Han X, Geng C, Jiang B, Huo Y, Luo J. Acute mechanical stretch promotes eNOS activation in venous endothelial cells mainly via PKA and Akt pathways. PLoS ONE, 2013, 8: e71359

86 Hsieh HJ, Liu CA, Huang B, Tseng AH, Wang DL. Shear-induced endothelial mechanotransduction: the interplay between reactive oxygen species (ROS) and nitric oxide (NO) and the pathophysiological implications. J Biomed Sci, 2014, 21: 3

87 Raaz U, Toh R, Maegdefessel L, Adam M, Nakagami F, Emrich FC, Spin JM, Tsao PS. Hemodynamic regulation of reactive oxygen species: implications for vascular diseases. Antioxid Redox Signal, 2014, 20: 914-928

88 Birukov KG. Cyclic stretch, reactive oxygen species, and vascular remodeling. Antioxid Redox Signal, 2009, 11: 1651-1667

89 Davies PF, Civelek M, Fang Y, Fleming I. The atherosusceptible endothelium: endothelial phenotypes in complex haemodynamic shear stress regions in vivo. Cardiovasc Res, 2013, 99: 315-327

90 Liu Y, Sweet DT, Irani-Tehrani M, Maeda N, Tzima E. Shc coordinates signals from intercellular junctions and integrins to regulate flow-induced inflammation. J Cell Biol, 2008, 182: 185-196

91 Dixit M, Loot AE, Mohamed A, Fisslthaler B, Boulanger CM, Ceacareanu B, Hassid A, Busse R, Fleming I. Gab1, SHP2, and protein kinase A are crucial for the activation of the endothelial NO synthase by fluid shear stress. Circ Res, 2005, 97: 1236-1244

92 Jin ZG, Wong C, Wu J, Berk BC. Flow shear stress stimulates Gab1 tyrosine phosphorylation to mediate protein kinase $\mathrm{B}$ and endothelial nitric-oxide synthase activation in endothelial cells. J Biol Chem, 2005, 280: 12305-12309

$93 \mathrm{Gu}$ H, Neel BG. The "Gab" in signal transduction. Trends Cell Biol, 2003, 13: 122-130

94 Lu Y, Xiong Y, Huo Y, Han J, Yang X, Zhang R, Zhu DS,
Klein-Hessling S, Li J, Zhang X, Han X, Li Y, Shen B, He Y, Shibuya M, Feng GS, Luo J. Grb-2-associated binder 1 (Gab1) regulates postnatal ischemic and VEGF-induced angiogenesis through the protein kinase A-endothelial NOS pathway. Proc Natl Acad Sci USA, 2011, 108: 2957-2962

95 Spagnoli LG, Villaschi S, Neri L, Palmieri G. Gap junctions in myo-endothelial bridges of rabbit carotid arteries. Experientia, 1982, 38: $124-125$

96 Chiu JJ, Chen LJ, Lee PL, Lee CI, Lo LW, Usami S, Chien S. Shear stress inhibits adhesion molecule expression in vascular endothelial cells induced by coculture with smooth muscle cells. Blood, 2003, 101: 2667-2674

97 Drummond HA, Gebremedhin D, Harder DR. Degenerin/epithelial $\mathrm{Na}^{+}$channel proteins: components of a vascular mechanosensor. Hypertension, 2004, 44: 643-648

98 Van der Heiden K, Hierck BP, Krams R, de Crom R, Cheng C, Baiker M, Pourquie MJ, Alkemade FE, DeRuiter MC, Gittenberger-de Groot AC, Poelmann RE. Endothelial primary cilia in areas of disturbed flow are at the base of atherosclerosis. Atherosclerosis, 2008, 196: 542-550

99 Davies PF. Flow-mediated endothelial mechanotransduction. Physiol Rev, 1995, 75: 519-560

100 Mayrovitz HN, Roy J. Microvascular blood flow: evidence indicating a cubic dependence on arteriolar diameter. Am J Physiol, 1983, 245: H1031-H1038

101 Langille BL, O’Donnell F. Reductions in arterial diameter produced by chronic decreases in blood flow are endothelium-dependent. Science, 1986, 231: 405-407

102 Bakker EN, Versluis JP, Sipkema P, VanTeeffelen JW, Rolf TM, Spaan JA, VanBavel E. Differential structural adaptation to haemodynamics along single rat cremaster arterioles. J Physiol, 2003, 548: 549-555

103 Bentley K, Philippides A, Ravasz Regan E. Do endothelial cells dream of eclectic shape? Dev Cell, 2014, 29: 146-158

104 Gimbrone MA Jr, García-Cardeña G. Vascular endothelium, hemodynamics, and the pathobiology of atherosclerosis. Cardiovasc Pathol, 2013, 22: 9-15

105 Grayson TH, Chadha PS, Bertrand PP, Chen H, Morris MJ, Senadheera S, Murphy TV, Sandow SL. Increased caveolae density and caveolin-1 expression accompany impaired NO-mediated vasorelaxation in diet-induced obesity. Histochem Cell Biol, 2013, 139: 309-321

106 Köhler R, Grundig A, Brakemeier S, Rothermund L, Distler A, Kreutz R, Hoyer J. Regulation of pressure-activated channel in intact vascular endothelium of stroke-prone spontaneously hypertensive rats. Am J Hypertens, 2001, 14: 716-721

107 Prasad RM, Jin X, Nauli SM. Sensing a sensor: identifying the mechanosensory function of primary cilia. Biosensors (Basel), 2014, 4: $47-62$

108 Aboualaiwi WA, Muntean BS, Ratnam S, Joe B, Liu L, Booth RL, Rodriguez I, Herbert BS, Bacallao RL, Fruttiger M, Mak TW, Zhou J, Nauli SM. Survivin-induced abnormal ploidy contributes to cystic kidney and aneurysm formation. Circulation, 2014, 129: 660-672

109 Salmon AH, Satchell SC. Endothelial glycocalyx dysfunction in disease: albuminuria and increased microvascular permeability. J Pathol, 2012, 226: 562-574

110 Salmon AH, Ferguson JK, Burford JL, Gevorgyan H, Nakano D, Harper SJ, Bates DO, Peti-Peterdi J. Loss of the endothelial glycocalyx links albuminuria and vascular dysfunction. J Am Soc Nephrol, 2012, 23: 1339-1350

111 Lopez-Quintero SV, Cancel LM, Pierides A, Antonetti D, Spray DC, Tarbell JM. High glucose attenuates shear-induced changes in endothelial hydraulic conductivity by degrading the glycocalyx. PLoS ONE, 2013, 8: e78954

Open Access This article is distributed under the terms of the Creative Commons Attribution License which permits any use, distribution, and reproduction in any medium, provided the original author(s) and source are credited. 